\title{
THE PREVALENCE OF DIABETIC RETINOPATHY AND MACULOPATHY AND THEIR RISK FACTORS IN THE NON-INSULIN-TREATED DIABETIC PATIENTS OF AN ENGLISH TOWN
}

\author{
JOHN M. SPARROW, BRUCE K. MCLEOD, TIM D. W. SMITH, \\ MICHAEL K. BIRCH and A. RALPH ROSENTHAL \\ Leicester
}

\begin{abstract}
SUMMARY
A total population study of the ocular status of all known non-insulin-treated diabetic patients resident in the English town of Melton Mowbray has been conducted. The population prevalence of non-insulin-treated diabetes in the town was 6.7/1000. There were 215 patients in the target population, with $65 \%$ of the resident survivors participating in the study. Further data on ocular status were gathered from hospital records, bringing the total percentage for whom some information on ocular status was available to $74 \%$. Corrected Snellen acuity was $6 / 12$ or better in $76 \%$ of patients and the overall prevalence rate for any diabetic retinopathy was $52 \%$, for proliferative retinopathy was $4 \%$, and for maculopathy requiring treatment was $10 \%$. In a multivariate analysis, risk factors for retinopathy and/or maculopathy included longer diabetic duration, female sex, higher blood pressure, the use of anti-hypertensive drugs and cigarette smoking.
\end{abstract}

Diabetic retinopathy is a leading cause of visual impairment among people of working age in Western society. ${ }^{1-3}$ Precise quantification of the prevalence of diabetic retinopathy in different communities is important for the planning and provision of health services both locally and nationally. Numerous studies have investigated the epidemiology of background and proliferative diabetic retinopathy, ${ }^{4-13}$ but there have been few studies which specifically examine the epidemiology of diabetic maculopathy. ${ }^{14-16}$

The identification of risk factors is important for the evolution of better management strategies for diabetic retinopathy. From previous studies possible risk factors for retinopathy in general have included diabetic duration, glycaemic control (blood glucose and glycosylated hae-

Correspondence to: Dr. John M. Sparrow, DPhil, FRCS, Department of Ophthalmology, University of Bristol, Bristol Eye Hospital, Lower Maudlin Street, Bristol BS1 2LX, UK. moglobin), type of diabetes (age at onset), diabetic treatment (insulin, oral hypoglycaemic, dietary), systemic hypertension, renal function/nephropathy, body mass, sex, HLA status, cigarette smoking, and elevated blood lipids. ${ }^{4,5,9-13,16-24}$ Despite the recognised importance of maculopathy as a cause of visual morbidity in diabetes, ${ }^{2,3,25,26}$ risk factors for diabetic maculopathy have received considerably less attention in the literature. Diabetic duration, age, sex, age at diagnosis, insulin use, higher glycosylated haemoglobin, diuretic use, systemic hypertension and proteinuria have been associated with diabetic macular oedema. ${ }^{14,16}$

In this study of a total population we report the prevalence and risk factors for diabetic retinopathy and diabetic macular oedema in the non-insulin-treated diabetics resident in the English market town of Melton Mowbray. Non-insulin-treated diabetics comprise the greater proportion of diabetics in the community, and quantification of the impact of diabetes on their visual status is relevant in terms of identification of need for care and service provision. This work completes the earlier report on the insulin-treated diabetics of this town, ${ }^{16}$ and together these two studies provide a reasonably complete statement on the ocular status of all known diabetics in this geographically well-defined community.

\section{METHOD}

\section{Population}

Melton Mowbray in Leicestershire is served by a single large general practice. An age/sex register of all patients registered with the town's practice is maintained by the Department of Epidemiology and Public Health of the University of Leicester. The town is demographically similar to England and Wales as a whole, ${ }^{27}$ and has a population of a little over 32,000. All known diabetics in the town were identified and invited to participate in an ocular examination. A previous report has described the method 
of ascertainment of the subjects and the findings for the insulin-treated group. ${ }^{16}$

\section{Patient Assessment}

The details of the method of examination have been described. ${ }^{16}$ Briefly, participants underwent a medical history, blood pressure measurement (Copal U-231 automatic sphygmomanometer), standard ocular refraction, slit lamp examination, direct and indirect ophthalmoscopic fundus examination through dilated pupils and 7-field stereo fundus photography. Stereo fundus photographs were graded by two independent observers. When disagreements occurred a consensus was reached by discussion and review of the images. Retinopathy was graded using the Wisconsin method, ${ }^{10}$ and maculopathy was graded separately using a slightly modified version of the ETDRS method. Clinically significant maculopathy was graded in the standard ETDRS manner, ${ }^{28}$ with an additional category being employed to describe the presence of maculopathy which was non-clinically significant (defined as haemorrhages, exudates or microaneurysms within $500 \mu \mathrm{m}$ of the fovea but without retinal thickening). Laser scars near the fovea were regarded as clinically significant maculopathy which had been treated. As many patients who had undergone laser treatment were unaware of the precise reason for this treatment, a positive history of macular oedema was not required for the diagnosis of previously treated macular oedema.

\section{Statistical Analysis}

Repeatability of the grading methods was assessed by the weighted kappa statistic ${ }^{29}$ and percentage exact agreement. Risk factors for retinopathy and maculopathy were assessed according to the patient's worse eye. For dependent variables employing ordinal scales a multivariate proportional odds regression was used, ${ }^{30}$ and for dependent variables with a binary scale a multivariate logistic regression was employed.

\section{RESULTS}

The population prevalence of diabetes in the town was
$10.8 / 1,000$, the prevalence of non-insulin-treated diabetes being $6.7 / 1,000$. Of the 215 patients with non-insulintreated diabetes who formed the target population for this study, 20 died during the study period and 5 moved away prior to their recruitment. (Four patients from the originally described population ${ }^{16}$ were excluded because they were found not to have diabetes.) Of the remaining 190 patients, $123(123 / 190=65 \%)$ attended the research clinic. Information on ocular status was gathered from hospital records of a further 25 patients ( 9 of whom had died/moved), bringing the total for whom some information on ocular status was known to 148 (148/ $199=74 \%)$. Mean age $( \pm S D$, minimum-maximum $)$ for these subjects was $67.7( \pm 11.9,28-91)$ years, mean diabetic duration was $7.2( \pm 5.8,1-35)$ years, mean age at diagnosis was $60.5( \pm 12.8,16-89)$ years, and $51 \%$ of the subjects were males. Patients for whom no information on ocular status was available were on average slightly older, and were more likely to be female, although these differences did not reach the $5 \%$ probability level.

\section{Photographic Grades of Retinopathy}

Photographs of sufficient quality for grading were available for 197 eyes in 101 subjects. Where there were disagreements in grading, final grades of retinopathy were reached by consensus. It is of interest to note that the independent grading of the photographs by two ophthalmologists (J.S. and M.B.) was associated with a 'good' level of inter-observer agreement. For retinopathy grading the weighted kappa statistic ${ }^{29}$ and percentage exact agreement were +0.71 and $77 \%$, and for maculopathy grading these statistics were +0.60 and $88 \%$ respectively. The 101 subjects with grading-quality photographs were classified for retinopathy and maculopathy according to their worse eye. These results are presented in Table I. Fifty per cent (95\% confidence interval (CI) $41 \%$ to $60 \%$ ) of patients had background retinopathy and 3\% (95\% CI $1 \%$ to $9 \%$ ) had evidence of regressed (previously treated) proliferative retinopathy. Of those with background retinopathy

Table I. Photographic grades of diabetic retinopathy and maculopathy in the worse eye for diabetic subjects

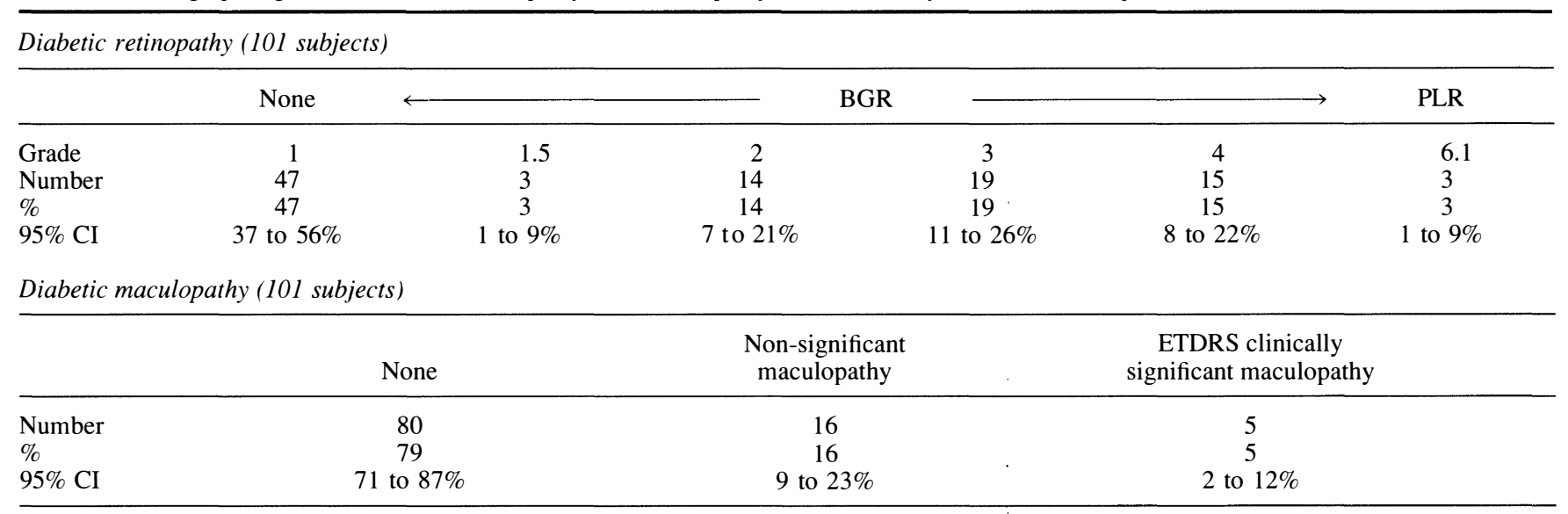

Retinopathy grades are those of the Wisconsin diabetic retinopathy grading method. ${ }^{10} \mathrm{BGR}$, background retinopathy; PLR, proliferative retinopathy; $1.5-3$, non-ischaemic background retinopathy; 4 , background retinopathy with features of ischaemia; 6.1 , regressed proliferative diabetic retinopathy. Non-significant maculopathy, maculopathy not reaching the ETDRS standard for clinically significant maculopathy; clinically significant maculopathy, ETDRS clinically significant maculopathy $;{ }^{28} 95 \% \mathrm{CI}, 95 \%$ confidence interval for percentage prevalence. 
Table II. Combined photographic and clinical grades of diabetic retinopathy and maculopathy in the worse eye for diabetic subjects examined in the research clinic

\begin{tabular}{|c|c|c|c|}
\hline \multicolumn{4}{|c|}{ Diabetic retinopathy (122 subjects) } \\
\hline & None & BGR & PLR \\
\hline $\begin{array}{l}\text { Number } \\
\% \\
95 \% \text { CI }\end{array}$ & $\begin{array}{c}60 \\
49 \\
40 \text { to } 58 \%\end{array}$ & $\begin{array}{c}59 \\
48 \\
40 \text { to } 57 \%\end{array}$ & $\begin{array}{c}3 \\
2 \\
0.8 \text { to } 8 \%\end{array}$ \\
\hline \multicolumn{4}{|c|}{ Diabetic maculopathy (121 subjects) } \\
\hline & \multicolumn{2}{|c|}{$\begin{array}{l}\text { No ETDRS clinically } \\
\text { significant } \\
\text { maculopathy }\end{array}$} & $\begin{array}{l}\text { ETDRS clinically } \\
\text { significant } \\
\text { maculopathy }\end{array}$ \\
\hline $\begin{array}{l}\text { Number } \\
\% \\
95 \% \text { CI }\end{array}$ & 89 tc & & $\begin{array}{c}6 \\
5 \\
2 \text { to } 11 \%\end{array}$ \\
\hline
\end{tabular}

Retinopathy grades are collapsed categories of the Wisconsin diabetic retinopathy grading method. ${ }^{10} \mathrm{BGR}$, background retinopathy (grades 1.5-5); PLR, proliferative retinopathy (6-8); ETDRS clinically significant maculopathy, ETDRS clinically significant maculopathy; ${ }^{28} 95 \%$ $\mathrm{CI}, 95 \%$ confidence interval for percentage prevalence.

$29 \%(15 / 51)$ had features of retinal ischaemia (grade 4). No patients in this group had active proliferative retinopathy or end-stage diabetic eye disease. Most patients had no maculopathy $(79 \%, 95 \%$ CI $71 \%$ to $87 \%)$; however, $5 \%$ (95\% CI $2 \%$ to $12 \%$ ) had ETDRS clinically significant maculopathy requiring laser treatment. Only 1 patient had previously undetected diabetic macular oedema which required treatment.

\section{Combined Clinical and Photographic Grades of Retinopathy}

The results from the clinical examination of the patients in the research clinic were used to supplement the photographic grading data where photographs were of inadequate quality for grading. In line with the limitations of the clinical assessments, the categories for these grades have been collapsed, so that retinopathy is presented (Table II) as none, background retinopathy or proliferative retinopathy, and maculopathy is presented as a dichotomy of either none or ETDRS clinically significant maculopathy. In the combined group of 123 patients only $2 \%(95 \% \mathrm{CI}$ $0.8 \%$ to $8 \%$ ) had previous or present proliferative diabetic retinopathy, with $49 \%$ (95\% CI $40 \%$ to $58 \%$ ) having no retinopathy. Five per cent (95\% CI $2 \%$ to $11 \%)$ of this group had ETDRS clinically significant diabetic maculopathy.

\section{Combined Research Clinic and Hospital Records Data}

Hospital records for 48 research clinic non-attenders were available and were reviewed. Of these 48 patients $25 \mathrm{had}$ attended the Leicester Royal Infirmary ophthalmology department, and for 22 of these patients data on retinopathy status were available. The records of the other 26 patients contained no information regarding their ocular status. Not surprisingly the patients attending the ophthalmology department appear to represent a group biased for ocular pathology. Fifty-nine per cent (13/22) had some retinopathy, with $14 \%(3 / 22)$ having past or present proliferative diabetic retinopathy. Forty-one per cent (9/22) had clinically significant maculopathy. Combining all the available data provides the results presented in Table III, where it will be noted that $52 \%$ (95\% CI $44 \%$ to $60 \%$ ) of patients had some retinopathy, $4 \%$ (95\% CI $2 \%$ to $9 \%$ ) had proliferative disease, and $10 \%$ (95\% CI $5 \%$ to $15 \%$ ) had clinically significant diabetic maculopathy. Using these data it is possible to make a minimum estimate of the overall prevalence of retinopathy in the non-insulintreated diabetics of the town as a whole. If we assume that patients with unknown ocular status had no retinopathy, then the minimum estimates for the whole town suggest that at least 35\% (75/215) had some retinopathy, with at least 3\% (6/215) having proliferative disease and at least $7 \%(15 / 215)$ having clinically significant diabetic maculopathy. If we regard proliferative retinopathy or maculopathy requiring laser treatment as serious disease, then a reasonable minimum estimate for 'serious diabetic eye disease' in this group of non-insulin-treated diabetics would be about $10 \%$. Conversely we may make the opposite extreme assumption and regard all patients for whom no data were available as having retinopathy, which would give a maximum estimate for retinopathy of $67 \%$ (145/ $215)$ and for maculopathy of $40 \%$ (86/215).

\section{Visual Acuity}

Snellen visual acuity was known for 144 subjects; for 123 of these the vision was the best corrected acuity, and for the remainder the information was taken from the patient's hospital records, representing either the spectacle or 'pin-hole' acuity, whichever was the better. The acuities in the subjects' better eye are presented in Table IV, where it is of note that $76 \%$ (95\% CI $69 \%$ to $83 \%$ ) of subjects had vision of $6 / 12$ or better, and that $6 \%$ (95\% CI $2 \%$ to $10 \%$ ) of patients were blind (vision $6 / 60$ or worse).

Table III. Combined photographic, research clinic and hospital record data for diabetic retinopathy and maculopathy in the worse eye

\begin{tabular}{|c|c|c|c|}
\hline \multicolumn{4}{|c|}{ Diabetic retinopathy (145 subjects) } \\
\hline & None & BGR & PLR \\
\hline Number & 70 & 69 & 6 \\
\hline & 48 & 48 & \\
\hline $95 \% \mathrm{CI}$ & 40 to $56 \%$ & 39 to $56 \%$ & 2 to $9 \%$ \\
\hline \multicolumn{4}{|c|}{ Diabetic maculopathy (144 subjects) } \\
\hline & \multicolumn{2}{|c|}{$\begin{array}{l}\text { No } \text { ETDRS }^{28} \text { clinically } \\
\text { significant } \\
\text { maculopathy }\end{array}$} & $\begin{array}{c}\text { ETDRS }^{28} \text { clinically } \\
\text { significant } \\
\text { maculopathy }\end{array}$ \\
\hline Number & \multicolumn{2}{|c|}{129} & 15 \\
\hline$\%$ & \multicolumn{2}{|c|}{90} & 10 \\
\hline $95 \%$ CI (per cent) & \multicolumn{2}{|c|}{$85-95$} & $5-15$ \\
\hline
\end{tabular}

Retinopathy grades are collapsed categories of the Wisconsin diabetic retinopathy grading method. ${ }^{10}$ BGR, background retinopathy (grades 1.5-5); PLR, proliferative retinopathy (6-8); 95\% CI, 95\% confidence interval for percentage prevalence. 
Table IV. Snellen acuity in the better eye of 144 non-insulin-treated diabetics

\begin{tabular}{lcccccccc}
\hline & \multicolumn{8}{c}{ Snellen visual acuity } \\
\cline { 2 - 8 } & $6 / 6$ & $6 / 9$ & $6 / 12$ & $6 / 18$ & $6 / 24$ & $6 / 36$ & $6 / 60$ & $<6 / 60$ \\
\hline$n$ & 48 & 31 & 30 & 17 & 5 & 4 & 2 & 7 \\
$\%$ & 33 & 22 & 21 & 12 & 3 & 3 & 1 & 5 \\
$95 \% \mathrm{CI}$ & 26 to $41 \%$ & 15 to $28 \%$ & 14 to $27 \%$ & 7 to $17 \%$ & 1 to $8 \%$ & 1 to $7 \%$ & 0.4 to $6 \%$ & 2 to $10 \%$ \\
\hline
\end{tabular}

95\% CI, 95\% confidence interval for percentage prevalence.

\section{Risk Factors for Retinopathy and Maculopathy}

Potential risk factors for diabetic retinopathy and maculopathy were examined in a number of multivariate models. Subjects were classified according to their worse eye for these analyses. The multivariate analyses took the form of proportional odds regression ${ }^{30}$ for rank-ordered dependent variables, and standard logistic regression for binary dependent variables: All models were non-sequential, thus each variable in the model is adjusted for the effects of each other variable. Age, diabetic duration and systolic and diastolic blood pressure were treated as continuous variables, while sex, smoking habit and the use of systemic anti-hypertensive medication were treated as factors. Analyses were performed within the three subgroups described above, the analyses being tailored according to the availability of data within each group. The analyses are summarised in Tables V and VI. The main points of interest are that for diabetic retinopathy the duration of diabetes is an important risk factor, and further that a higher systolic blood pressure is associated with an increased risk of retinopathy. For diabetic maculopathy, duration of diabetes is likewise an important risk factor,

Table V. Multivariate risk factor analysis for diabetic retinopathy in non-insulin-treated diabetics

\begin{tabular}{lccc}
\hline & Estimate & $95 \% \mathrm{CI}$ & $p$ \\
\hline Wisconsin photographic & grades & & \\
Age & -0.020 & \pm 0.049 & $\mathrm{NS}$ \\
Sex (F) & 0.45 & \pm 0.96 & $\mathrm{NS}$ \\
Duration & 0.17 & \pm 0.092 & 0.00041 \\
Smoking (previous) & 0.73 & \pm 1.25 & $\mathrm{NS}$ \\
Smoking (current) & 0.30 & \pm 1.30 & $\mathrm{NS}$ \\
Treated BP & 0.52 & \pm 0.97 & $\mathrm{NS}$ \\
Systolic BP & 0.023 & \pm 0.018 & 0.011 \\
Diastolic BP & 0.011 & \pm 0.037 & $\mathrm{NS}$ \\
Photographic + clinical grades & & \\
(none, background, proliferative) & & \\
Age & -0.015 & \pm 0.048 & $\mathrm{NS}$ \\
Sex (F) & 0.66 & \pm 0.93 & $\mathrm{NS}$ \\
Duration & 0.12 & \pm 0.093 & 0.013 \\
Smoking (previous) & 0.63 & \pm 1.19 & $\mathrm{NS}$ \\
Smoking (current) & 0.44 & \pm 1.23 & $\mathrm{NS}$ \\
Treated BP & 0.39 & \pm 0.94 & $\mathrm{NS}$ \\
Systolic BP & 0.019 & \pm 0.017 & 0.033 \\
Diastolic BP & -0.005 & \pm 0.035 & $\mathrm{NS}$ \\
Photographic + clinical grades + hospital records & \\
(none, background, proliferative) & & \\
Age & 0.0028 & \pm 0.0051 & $\mathrm{NS}$ \\
Sex (F) & 0.26 & \pm 0.66 & $\mathrm{NS}$ \\
Duration & -0.0003 & \pm 0.0027 & $\mathrm{NS}$ \\
\hline
\end{tabular}

Estimate, equivalent to relative risk in this type of analysis; $95 \% \mathrm{CI}$, 95\% confidence interval for estimate; treated BP, use of systemic antihypertensive medication; NS, not significant. with female sex, higher systolic blood pressure and the use of anti-hypertensive medication also contributing to the risk. Current cigarette smoking represented a marginal risk factor for maculopathy.

\section{DISCUSSION}

The findings of this survey of a total population confirm the importance of retinopathy and maculopathy in noninsulin-treated diabetic patients, who comprised more than half the diabetics in Melton Mowbray. By augmenting the information gathered at the research clinic (attendance rate $65 \%$ ) with data from hospital records, the ocular status of $74 \%$ of the non-insulin-treated diabetic population was known. The attendance rate of the present group of non-insulin-treated patients was less than that for the previously reported insulin-treated group $(86 \%)$, and there were also several non-insulin-treated patients lost to the study as a result of death or moving away from the study area. The lower attendance and greater population attrition were probably influenced by the fact that the mean age of the non-insulin-treated group was 20 years greater than the mean age of those using insulin, ${ }^{16}$ and further that the

Table VI. Multivariate risk factor analysis for diabetic maculopathy in non-insulin-treated diabetics

\begin{tabular}{|c|c|c|c|}
\hline & Estimate & $95 \% \mathrm{CI}$ & $p$ \\
\hline \multicolumn{4}{|c|}{$\begin{array}{l}\text { Photographic grades } \\
\text { (none, non-significant, ETDRS clinically significant) }\end{array}$} \\
\hline Age & -0.024 & \pm 0.071 & NS \\
\hline $\operatorname{Sex}(F)$ & 1.35 & \pm 1.39 & 0.056 \\
\hline Duration & 0.19 & \pm 0.12 & 0.0024 \\
\hline Smoking (previous) & 1.92 & \pm 2.37 & NS \\
\hline Smoking (current) & 2.23 & \pm 2.43 & 0.073 \\
\hline Treated BP & 1.64 & \pm 1.52 & 0.034 \\
\hline Systolic BP & 0.024 & \pm 0.024 & 0.046 \\
\hline Diastolic BP & 0.013 & \pm 0.049 & NS \\
\hline \multicolumn{4}{|c|}{$\begin{array}{l}\text { Photographic + clinical grades } \\
\text { (none + non-significant, ETDRS clinically significant) }\end{array}$} \\
\hline Age & -0.10 & \pm 0.22 & NS \\
\hline $\operatorname{Sex}(F)$ & 4.95 & \pm 4.45 & 0.029 \\
\hline Duration & 0.51 & \pm 0.45 & 0.027 \\
\hline Smoking (previous) & 7.98 & \pm 70.56 & NS \\
\hline Smoking (current) & 10.16 & \pm 70.54 & NS \\
\hline Treated BP & 3.21 & \pm 4.64 & NS \\
\hline Systolic BP & 0.033 & \pm 0.078 & NS \\
\hline Diastolic BP & 0.10 & \pm 0.15 & NS \\
\hline \multicolumn{4}{|c|}{$\begin{array}{l}\text { Photographic }+ \text { clinical grades }+ \text { hospital records } \\
\text { (none + non-significant, ETDRS clinically significant) }\end{array}$} \\
\hline Age & 0.032 & \pm 0.056 & NS \\
\hline $\operatorname{Sex}(F)$ & 1.69 & \pm 1.42 & 0.020 \\
\hline Duration & 0.17 & \pm 0.092 & 0.00030 \\
\hline
\end{tabular}

Estimate, equivalent to relative risk in this type of analysis; $95 \% \mathrm{CI}$, 95\% confidence interval for estimate; treated BP, use of systemic antihypertensive medication; NS, not significant. 
non-insulin-treated patients were examined in the second phase of the study, thus being exposed to a longer delay between identification and recruitment. Among the noninsulin-treated subjects there were no significant age or sex differences between attenders and non-attenders. From the combined studies there was information on the ocular status of $79 \%(216 / 330)$ of the surviving resident diabetics of the town.

In the various subgroups of the non-insulin-treated patients just under $50 \%$ of patients had no retinopathy in either eye, just under $50 \%$ had background retinopathy only in their worse eye, $2-4 \%$ had proliferative retinopathy in their worse eye, and 5-10\% had clinically significant maculopathy requiring laser treatment. The equivalent figures for the insulin-treated subjects were $50 \%$ with no retinopathy, $41 \%$ with background retinopathy only, $9 \%$ with proliferative or advanced disease, and $14 \%$ with clinically significant ${ }^{*}$ maculopathy. ${ }^{16}$ These differences are consistent with previous reports in which diabetics on insulin treatment have higher rates of retinopathy and maculopathy. ${ }^{9,11,12,14,31}$

Previous population-based studies of non-insulintreated diabetics have provided similar results for retinopathy. Comparison between the present study and the Wisconsin Epidemiologic Study of Diabetic Retinopathy (WESDR) of Klein et al. is the most relevant. Both were population-based studies and the same methods of quantification of retinopathy and maculopathy were employed. Klein et al. found slightly less background retinopathy $(36 \%)$, the same prevalence of proliferative retinopathy (3\%), but less macular oedema (3.7\%) among their 696 non-insulin-treated patients. ${ }^{11,14}$ In the present study our photographic grading and research clinic assessments demonstrated a comparable maculopathy prevalence of $5 \%$, but inclusion of the data from hospital records on nonattenders increased this prevalence to $10 \%$. Not surprisingly the hospital-based subgroup of non-attenders was biased towards those with more severe pathology.

Comparisons between studies become more difficult when the methods of assessing retinopathy are dissimilar; however, West $e t$ al. reported from a large multinational study a retinopathy prevalence of $21 \%$ for any retinopathy and $1.4 \%$ for proliferative retinopathy among 2711 noninsulin-treated patients. ${ }^{9}$ On the Island of Falseter, Denmark, Nielsen found background retinopathy in 38\% and proliferative retinopathy in $3.3 \%$ of 306 diabetics treated with oral hypoglycaemic agents (mean age 71 years). ${ }^{8}$ Jerneld and Algvere reported on diabetics treated with oral hypoglycaemic agents from the Island of Gotland, Sweden. In their random sample of 140 patients, $17 \%$ were found to have some retinopathy, and $1.4 \%$ to have proliferative retinopathy (mean age 73 years). ${ }^{6}$ Segato et al. reported on a population-based sample of diabetics in the Veneto region of Northern Italy. Among the non-insulin-treated patients $25 \%$ were found to have retinopathy. ${ }^{12}$ In a Swiss national stratified population sample retinopathy was found in only $13 \%$ of the 94 noninsulin-treated subjects. ${ }^{24}$ In a group of predominantly
(78\%) non-insulin-treated elderly diabetics (age $>60$ years) in Oxford, Neil et al. found retinopathy in $26 \%$ of subjects. Interestingly, their finding of $76 \%$ of patients with visual acuity of $6 / 12$ or better is identical to our own. ${ }^{32}$ Our results have demonstrated a higher prevalence of retinopathy among non-insulin-treated diabetics than most previous studies. This is probably due to the use of a more sensitive method of diagnosis of retinopathy, i.e. stereo retinal photographs. Our findings are more comparable with those of Klein et al. ${ }^{11,14}$ who used the same photographic method of assessment.

Risk factors for background or proliferative retinopathy in the present study included longer duration of diabetes and higher systolic blood pressure (Table V). Diabetic duration and increased systolic blood pressure have previously been reported as risk factors for retinopathy in non-insulin-treated patients, ${ }^{6,11,18}$ although not all studies of non-insulin-treated patients have demonstrated a risk from hypertension. ${ }^{21}$

Risk factors for maculopathy included longer diabetic duration, female sex, higher systolic blood pressure, the use of anti-hypertensive medication, and a marginal effect of cigarette smoking (Table VI). Previous data on risk factors for maculopathy are scarce. To our knowledge the only significant study of risk factors for maculopathy in non-insulin-treated diabetic patients in the WESDR, in which Klein et al. reported that macular oedema was associated with longer diabetic duration, higher systolic blood pressure, and marginally with higher glycosylated haemoglobin. ${ }^{14}$ Systemic hypertension was found as a risk factor for macular oedema in the insulin-treated patients in Melton Mowbray ${ }^{16}$ and a similar association has previously been reported in a small group of mixed diabetics. ${ }^{33}$ Our finding of a marginal effect of smoking in association with macular oedema is more controversial. There have been conflicting reports on the importance of smoking as a risk factor for diabetic retinopathy. ${ }^{17,34,35} \mathrm{To}$ our knowledge, however, there have been no previous studies specifically addressing the question of smoking as a risk factor for diabetic maculopathy. It is possible that the previously conflicting reports have resulted from failure to examine the effects of this possible risk factor on retinopathy and maculopathy separately. This finding warrants further investigation.

The present report on diabetic retinopathy and maculopathy in non-insulin-treated patients completes the total population study of diabetics resident in the town of Melton Mowbray. These two reports have provided valuable prevalence data for diabetic retinopathy and maculopathy in an English population, which is known to be demographically representative of England and Wales as a whole. ${ }^{27}$ Our data suggest that in Britain sight-threatening diabetic maculopathy, particularly among non-insulintreated diabetics, may be commoner than has previously been assumed from population-based studies in North America. Our findings confirm the importance of diabetic duration and systemic hypertension as risk factors for diabetic retinopathy and maculopathy, and suggest that ciga- 
rette smoking may be a risk factor specific to diabetic maculopathy.

The authors are grateful to Dr. John Thompson, Department of Ophthalmology, University of Leicester, for statistical advice, and to the Anne Allerton Fund and the Trent Regional Health Authority for financial support.

Key words: Diabetic retinopathy, Non-insulin treatment, Prevalence, Risk factors.

\section{REFERENCES}

1. Sorsby A. The incidence and causes of blindness in England and Wales 1963-1968. Reports in public health and medical subjects 128. London: HMSO, 1972.

2. Klein R, Klein BEK, Moss SE. Visual impairment in diabetes. Ophthalmology 1984;91:1-9.

3. Moss SE, Klein R, Klein BEK. The incidence of vision loss in a diabetic population. Ophthalmology 1988;95:1340-8.

4. Rand LI, Krolewski AS, Aiello LM, Warram JH, Baker RS, Maki T. Multiple factors in the prediction of risk factors for proliferative diabetic retinopathy. N Engl J Med 1985;313: 1433-8.

5. Constable IJ, Knuiman MW, Welborn TA, Cooper RL, Stanton KM, McCann VJ, Grose GC. Assessing the risk of diabetic retinopathy. Am J Ophthalmol 1984;97:53-61.

6. Jerneld B, Algvere P. Prevalence of retinopathy in diabetes treated with oral antihyperglycaemic agents. Acta Ophthalmol 1985;63:535-40.

7. Nielsen NV. Diabetic retinopathy. I. The course of retinopathy in insulin-treated diabetics. A one-year epidemiological cohort study of diabetes mellitus on the island of Falseter, Denmark. Acta Ophthalmol 1984;62:256-65.

8. Nielsen NV. Diabetic retinopathy. II. The course of retinopathy in diabetics treated with oral hypoglycaemic agents and diet regime alone. A one-year epidemiological cohort study of diabetes mellitus on the island of Falseter, Denmark. Acta Ophthalmol 1984;62:266-73.

9. West KM, Ahuja MMS, Bennett PH, Grab B, Grabauskas V, Mateo-de-Acosta $\mathrm{O}$, et al. Interrelationships of microangiopathy, plasma glucose and other risk factors in 3583 diabetic patients: a multinational study. Diabetologia 1982;22: 412-20.

10. Klein R, Klein BEK, Moss SE, Davis MD, DeMets DL. The Wisconsin epidemiologic study of diabetic retinopathy. II. Prevalence and risk of diabetic retinopathy when age at diagnosis is less than 30 years. Arch Ophthalmol 1984;102: 520-6.

11. Klein R, Klein BEK, Moss SE, Davis MD, DeMets DL. The Wisconsin epidemiologic study of diabetic retinopathy. III. Prevalence and risk of diabetic retinopathy when age at diagnosis is 30 or more years. Arch Ophthalmol 1984;102: 527-32.

12. Segato T, Midena E, Grigoletto F, Zucchetto M, Fedele D, Piermarocchi S, et al. The epidemiology and prevalence of diabetic retinopathy in the Veneto region of north-east Italy. Diabetic Med 1991;8 (Symposium):S11-S16.

13. Kostraba JN, Klein R, Dorman JS, Becker DJ, Drash AL, Maser RE, Orchard TJ. The epidemiology of diabetes complications study. IV. Correlates of diabetic background and proliferative retinopathy. Am J Epidemiol 1991;133: 381-91.

14. Klein R, Klein BEK, Moss SE, Davis MD, DeMets DL. The Wisconsin epidemiologic study of diabetic retinopathy. IV. Diabetic macular edema. Ophthalmology 1984;91: 1464-74.
15. Klein R, Klein BEK, Moss SE, Davis MD, DeMets DL. The Wisconsin epidemiologic study of diabetic retinopathy. XI. The incidence of macular oedema. Ophthalmology 1989;96: 1501-10.

16. McLeod BK, Thompson JR, Rosenthal AR. The prevalence of retinopathy in the insulin-requiring diabetic patients of an English country town. Eye 1988;2:424-30.

17. Mühlhauser I, Sawicki P, Berger M. Cigarette smoking as a risk factor for macroproteinuria and proliferative retinopathy in type 1 (insulin-dependent) diabetes. Diabetologia 1986;29:500-2.

18. Barnett AH, Britton JR, Leatherdale BA. Study of possible risk factors for severe retinopathy in non-insulin dependent diabetes. BMJ 1983;287:529.

19. Nathan DM, Singer DE, Godine JE, Harrington CH, Perlmuter LC. Retinopathy in older type II diabetics: association with glucose control. Diabetes 1986;35:797-801.

20. Nelson RG, Wolfd JA, Horton MB, Pettitt DJ, Bennett PH, Knowler WC. Proliferative retinopathy in NIDDM: incidence and risk factors in Pima Indians. Diabetes 1989;38: 435-40.

21. Klein R, Klein BEK, Moss SE, Davis MD, DeMets DL. Is blood pressure a predictor of the incidence or progression of diabetic retinopathy? Arch Intern Med 1989;149:2427-32.

22. Knowler WC, Bennett PH, Ballintine EJ. Increased incidence of retinopathy in diabetics with elevated blood pressure: a six-year follow-up study in Pima Indians. N Engl J Med 1980;302:645-50.

23. Brinchmann-Hansen O, Dahl-Jorgensen K, Sandvik L, Hanssen KF. Blood glucose concentrations and progression of diabetic retinopathy: the seven-year results of the Oslo study. BMJ 1992;304:19-22.

24. Teuscher A, Schnell H, Wilson PWF. Incidence of diabetic retinopathy and relationship to baseline plasma glucose and blood pressure. Diabetes Care 1988;11:246-51.

25. Moriarty BJ, Dunn DT, Moriarty AP. Diabetic maculopathy in a Jamaican population. Int Ophthalmol 1989;13:301-3.

26. ETDRS Study Group. Early photocoagulation for diabetic retinopathy. ETDRS report no. 9. Ophthalmology 1991;98: 776-85.

27. Clarke M, Clarke S, Odell A. The elderly at home: health and social status. Health Trends 1984;16:3-7.

28. ETDRS Study Group. Photocoagulation for diabetic macular oedema. ETDRS report no. 1. Arch Ophthalmol 1985; 103:1798-806.

29. Hall JN. Inter-rater reliability of ward rating scales. Br J Psychiatry 1974; 125:248-55.

30. McCullagh P. Regression models for ordinal data. J R Stat Soc 1980;B42:109-42.

31. Grey RHB, Malcolm N, O’Reilly D, Morris A. Ophthalmic survey of a diabetic clinic. I. Ocular findings. Br J Ophthalmol 1986;70:797-803.

32. Neil HAW, Thompson AV, Thorogood M, Fowler GH, Mann JI. Diabetes in the elderly: the Oxford community diabetes study. Diabetic Med 1989;6:608-13.

33. Deutsch TA, O'Riordan JF, Ernest JT, Goldstick TK. Systemic blood pressure and diabetic macular oedema. Invest Ophthalmol Vis Sci 1983; (ARVO Suppl) 24:80.

34. West KM, Erdreich LS, Stober JA. Absence of a relationship between smoking and diabetic microangiopathy. Diabetes Care 1980;3:250-2.

35. Moss SE, Klein R, Klein BEK. Association of cigarette smoking with diabetic retinopathy. Diabetes Care 1991;14: 119-26. 